\title{
Hydrogen Permeation Behavior of Scratch Formed on Zn Coated Steels in Simulated Atmospheric Corrosion Environment
}

\author{
Kei SAKATA, ${ }^{1) *}$ Masatoshi SAKAIRI ${ }^{2)}$ and Junichiro KINUGASA ${ }^{3)}$ \\ 1) Graduate School of Engineering, Hokkaido University, Kita-13, Nishi-8, Kita-ku, Sapporo, Hokkaido, Japan. \\ 2) Faculty of Engineering, Hokkaido University, Kita-13, Nishi-8, Kita-ku, Sapporo, Hokkaido, Japan. \\ 3) Materials Research Laboratory, Kobe Steel Ltd., 1-5-5 Takatsukadai, Nishi-ku, Kobe, Hyogo, 651-2271 Japan.
}

(Received on May 29, 2020; accepted on August 3, 2020)

\begin{abstract}
In this study, the electrochemical hydrogen permeation technique was introduced to investigate the relationship between scratch shape and hydrogen permeation on of $\mathrm{Zn}$ coated steel with wet and dry cyclic corrosion. Six kinds of scratches with different aspect ratio (width/length) and area were fabricated by focused pulsed Nd: YAG laser irradiation. Hydrogen permeation currents with each scratches formed on Zn coated steels were investigated. Regardless of scratch shapes, the peaks were recorded in hydrogen permeation currents during wetting and $\mathrm{Zn}$ corrosion products were observed around and on the formed scratches. The total hydrogen permeation charges calculated from hydrogen permeation currents depended on aspect ratio and area of scratch. It is suggested that Zn corrosion products easily covered high aspect ratio scratch and prevented hydrogen entry. In detail change of hydrogen permeation currents during wet and dry corrosion tests was also explained based on coverage and composition of Zn corrosion products.
\end{abstract}

KEY WORDS: electrochemical permeated hydrogen detection; Zn coated steel; scratch; laser fabrication; simulated atmospheric corrosion environment.

\section{Introduction}

In recent years, the strength of steels has been increasing for the purpose of reducing the weight of structures. For example, the cable of Akashi-Kaikyo Bridge, the longest suspension bridge in the world, uses high-strength steel wires exceeding $1770 \mathrm{MPa}$. This was much higher than the tensile strength of $1550-1600 \mathrm{MPa}$ at that time. ${ }^{1)}$ It is well known that the high-strength steels have a high susceptibility to hydrogen embrittlement or delayed fracture. $^{2-4)}$ Hydrogen embrittlement and delayed fracture have become important issue recently. ${ }^{5-14)}$ It is also pointed out that delayed fracture occurs due to the entry of hydrogen generated by the atmospheric corrosion. ${ }^{15)}$

In the practical use of steels including high strength steels, atmospheric corrosion plays an important role in the hydrogen generation. Therefore, $\mathrm{Zn}$ coating is widely used to reduce the corrosion rate of the steels. $\mathrm{Zn}$ is known to have excellent corrosion resistance in the atmosphere, and the corrosion rate is about $1 / 10$ to $1 / 100$ lower than that of steel. ${ }^{16)}$ However, if a scratch is formed on the $\mathrm{Zn}$ coating, more serious corrosion occurs and the amount of hydrogen entry increases. ${ }^{17,18)}$ Figure 1 shows a schematic representative of $\mathrm{Zn}$ sacrificial

\footnotetext{
* Corresponding author: E-mail: k.sakata@frontier.hokudai.ac.jp
}

protection to steel and hydrogen formation and entry. Zn dissolves near the scratch $\left(\mathrm{Zn} \rightarrow \mathrm{Zn}^{2+}+2 \mathrm{e}^{-}\right)$and hydrogen generation reaction $\left(\mathrm{H}_{2} \mathrm{O}+\mathrm{e}^{-} \rightarrow \mathrm{H}_{\mathrm{ad}}+\mathrm{OH}^{-}\right)$increases at exposed steel area. The $\mathrm{Zn}$ sacrificial protection to steel increase hydrogen entry $\left(\mathrm{H}_{\mathrm{ad}} \rightarrow \mathrm{H}_{\mathrm{ab}}\right)$. This also increases the risk of formation of cracks by hydrogen embrittlement.

Zn sacrificial protection to steel corrosion occurs within a certain region around steel/Zn boundary. Hydrogen generation reaction and hydrogen entry may be affected by scratch shape and area. The amount of hydrogen permeation could also change with aspect ratio of scratch and scratch area. In this paper, the effects of the scratch shape and area on the

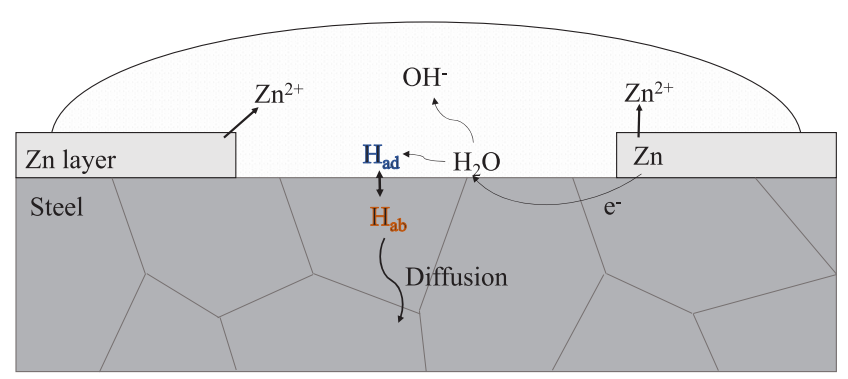

Fig. 1. Schematic representation of $\mathrm{Zn}$ sacrificial protection to steel and hydrogen formation and entry. (Online version in color.) 
hydrogen permeation behavior of $\mathrm{Zn}$ coated steel during wet and dry cycle corrosion were investigated with microelectrochemical hydrogen detection cell.

\section{Experimental}

\subsection{Specimens}

$\mathrm{Zn}$ coated steels sheets $(15 \times 30 \times 0.5 \mathrm{~mm})$ were used as specimens. One side of the specimen for hydrogen detection side was ground with $\mathrm{SiC}$ abrasive paper up to \#1500 grit size in order to remove the $\mathrm{Zn}$ precoated layer, then, the surface was plated electrochemically with $\mathrm{Ni}$ in a $0.312 \mathrm{kmol} \mathrm{m}^{-3} \mathrm{NiSO}_{4}-0.781 \mathrm{kmol} \mathrm{m}^{-3} \mathrm{H}_{3} \mathrm{BO}_{3}$ solution at $4 \mathrm{~mA} \mathrm{~cm}^{-2}$ current for $720 \mathrm{~s}$. The thickness of Ni plated layer was $1 \mu \mathrm{m}$. The other side of the specimen (the hydrogen entry side of the specimens) was irradiated by pulsed Nd:YAG laser (wavelength $532 \mathrm{~nm}$, pulse duration 3-5 ns, pulse frequency $10 \mathrm{~s}^{-1}$, and power $20 \mathrm{~mW}$ at the front of the lens) in the highly purified water to form the scratches. Two types size of scratch areas, $2.07 \mathrm{~mm}^{2}$ and $4.67 \mathrm{~mm}^{2}$, were formed. The shapes of $2.07 \mathrm{~mm}^{2}$ scratches were controlled to be $1440 \times 1440 \mu \mathrm{m}^{2}$ (aspect ratio: 1), $2160 \times 960 \mu \mathrm{m}^{2}$ (aspect ratio: 2.25 ) and $4320 \times 480 \mu \mathrm{m}^{2}$ (aspect ratio: 9) by scanning of the laser beam. The shapes of $4.67 \mathrm{~mm}^{2}$ scratches were controlled to be $2160 \times 2160$ $\mu \mathrm{m}^{2}$ (aspect ratio: 1), $2880 \times 1620 \mu \mathrm{m}^{2}$ (aspect ratio: 1.77) and $4320 \times 1080 \mu \mathrm{m}^{2}$ (aspect ratio: 4). Figure 2 shows surface optical images of scratches formed on the specimen. Before the wet and dry corrosion tests, the specimens were cleaned in highly purified water and ethanol using ultrasonic baths for $300 \mathrm{~s}$.

\subsection{Wet and Dry Corrosion Tests}

In the hydrogen detection cell, Pt wires were used as the counter (C.E.) and the reference electrodes (R.E.). The potential difference between $\mathrm{Pt}$ electrode in $1 \mathrm{kmol} \mathrm{m}^{-3}$ $\mathrm{NaOH}$ solution and $\mathrm{Ag} / \mathrm{AgCl}$ sat. $\mathrm{KCl}$ was $-20 \mathrm{mV}$. The cell was filled with $1 \mathrm{kmol} \mathrm{m}^{-3} \mathrm{NaOH}$ in the hydrogen detection cell. The specimen of the hydrogen detection (the nickel plated) side was placed on the cell. It was ensured that there were no bubbles in the cell. The cell was set in humidity and temperature control chamber. Figure 3 shows the schematic outline of the equipment for the wet and dry corrosion tests. To measure the hydrogen, hydrogen detection side of the specimen was polarized at $-30 \mathrm{mV}$ vs. $\mathrm{Pt}$ (R. E.) during the tests. The applied anodic potential was sufficient to ionize any hydrogen reaching at the surface after permeating through the specimen. After the current of the hydrogen detection cell reached a sufficiently low and steady state value about $5 \mathrm{nA}$ (about $86.4 \mathrm{ks}$ after the potential was applied), $10 \mu \mathrm{L}$ of $0.1 \mathrm{kmol} \mathrm{m}^{-3} \mathrm{NaCl}$ solution was dropped on solution on the center of the scratch.

Immediately after dropping, wet and dry cyclic corrosion test and the measurement of hydrogen permeation current were started. Figure 4 shows the changes of relative humidity $(\% \mathrm{RH})$ and temperature with time for one cycle $(6 \mathrm{~h})$ of the wet and dry cyclic corrosion test. One cycle is divided into four processes; $1 \mathrm{~h}$ wetting process (maintained at 303

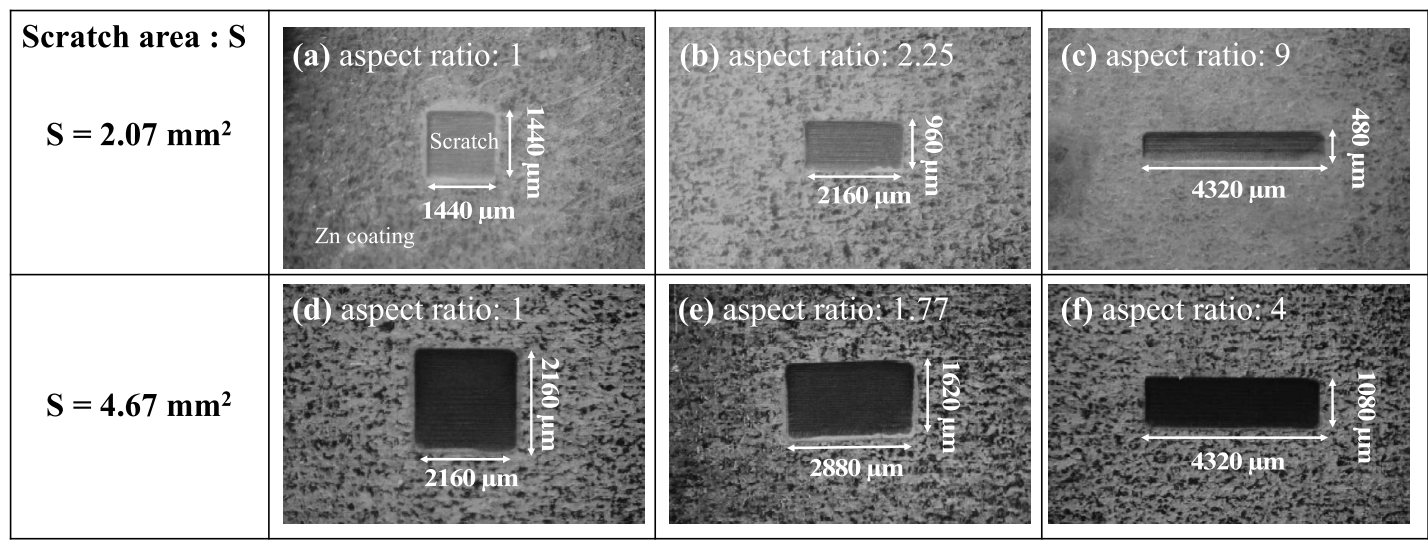

Fig. 2. Surface optical images of scratch formed on specimens. Aspect ratio; (a) 1, (b) 2.25, (c) 9, (d) 1, (e) 1.77, and (f) 4 .

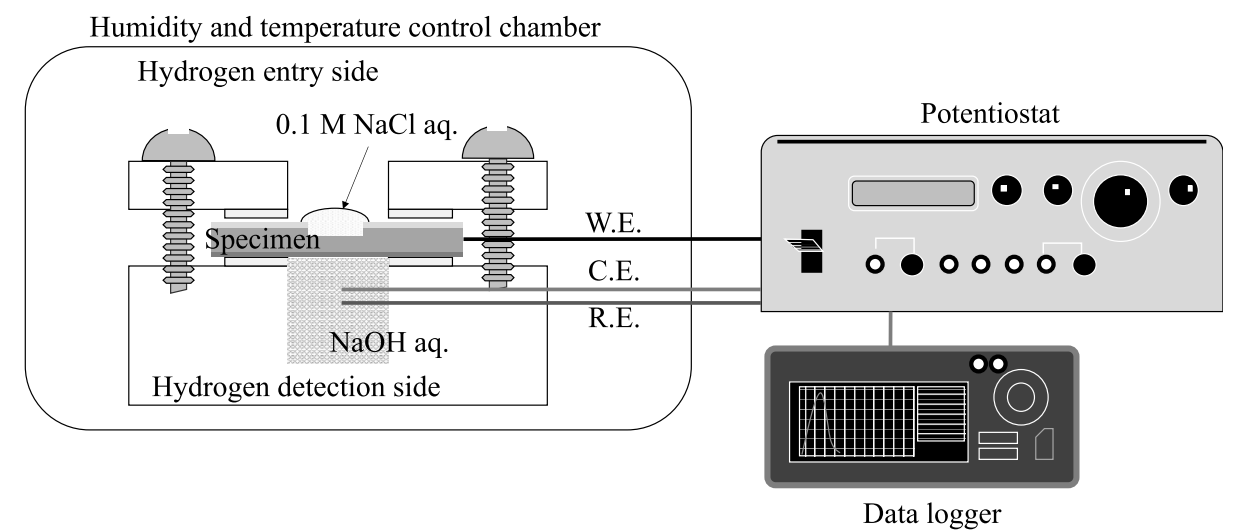

Fig. 3. Schematic outline of the equipment for the wet and dry corrosion tests. 


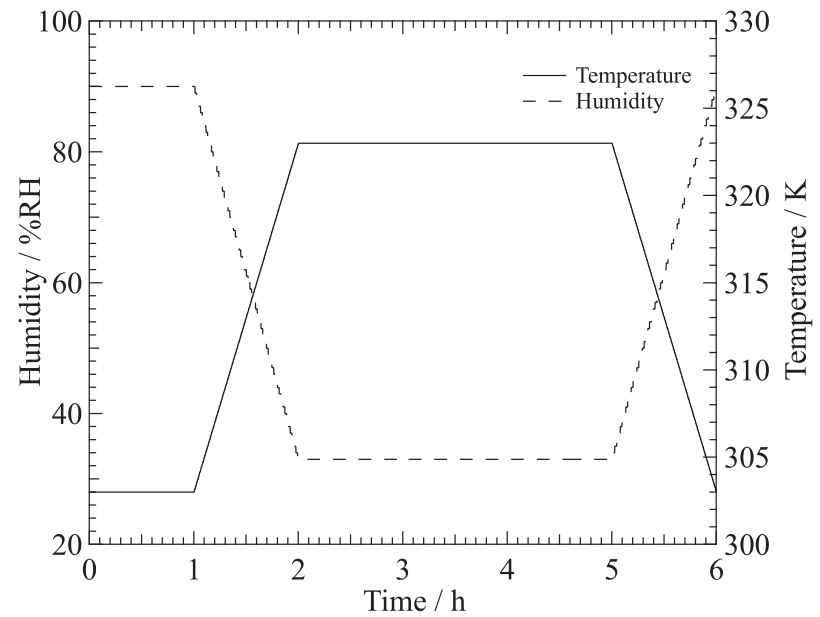

Fig. 4. Schematic representation of changes in relative humidity and temperature in the chamber during one cycle of the wet and dry corrosion test.

$\mathrm{K}, 90 \% \mathrm{RH}), 1 \mathrm{~h}$ heating process, $3 \mathrm{~h}$ drying process (323 $\mathrm{K}, 33 \% \mathrm{RH})$ and $1 \mathrm{~h}$ cooling process. The hydrogen permeation currents ware measured for $72 \mathrm{~h}$ (12 cycles). Three specimens at same aspect ratio and area were carried out.

Ootsuka et al. reported that the measured current was also influenced on the temperature change. ${ }^{19)}$ The current depending on temperature change was measured by masking using samples which surface did not to expose to environment (no corrosion occurred during wet and dry cycles). The hydrogen permeation current was calculated by subtracting the current depending on temperature change from the current measured during wet and dry corrosion test.

\subsection{Surface Observation and Analysis}

The surfaces of the specimens after the tests were observed by an optical microscope and a scanning electron microscope (SEM). An energy dispersive X-ray spectroscope (EDS), Raman spectroscope and Auger electron spectroscope (AES) were used to analyze the surface of the specimens. A green laser with $532 \mathrm{~nm}$ wave length was used for Raman spectroscope measurements. An acceleration voltage of $10.0 \mathrm{keV}$ and beam current of $10 \mathrm{nA}$ were used for SEM and AES analysis.

\section{Results and Discussion}

\subsection{Hydrogen Permeation Current during Wet and Dry Corrosion Tests}

The hydrogen permeation currents measured during wet and dry cyclic corrosion tests of specimens with different scratch shapes are shown in Fig. 5 along with the time change of temperature and humidity. Independent of scratch shape, the peaks are observed in hydrogen permeation currents during wetting period. In the first cycle, the reaction takes place under the formed droplets, whereas in the second and subsequent cycles, the reaction takes place under a thin liquid solution film formed on the once dried surface. This is the reason why there are the large peaks are observed only in the first cycle for of each scratch shape.

In order to elucidate the hydrogen permeation behavior in each cycle, the permeation current is integrated for each cycle to determine the amount of charge (Fig. 6). The plots are the

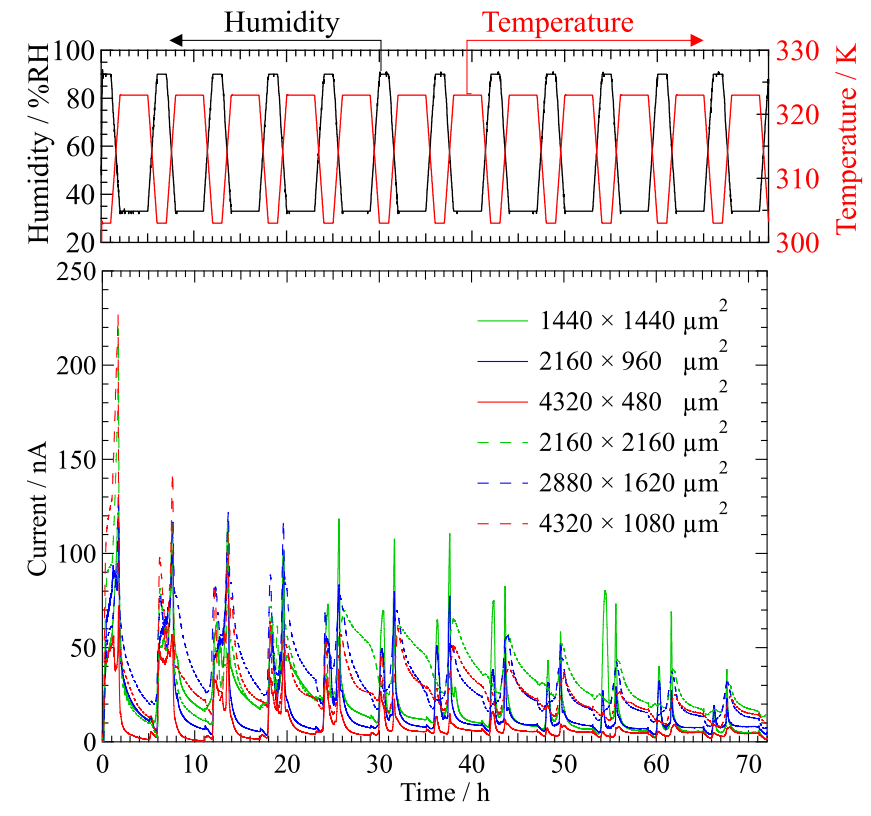

Fig. 5. Changes in hydrogen permeation current, humidity and temperature. (Online version in color.)

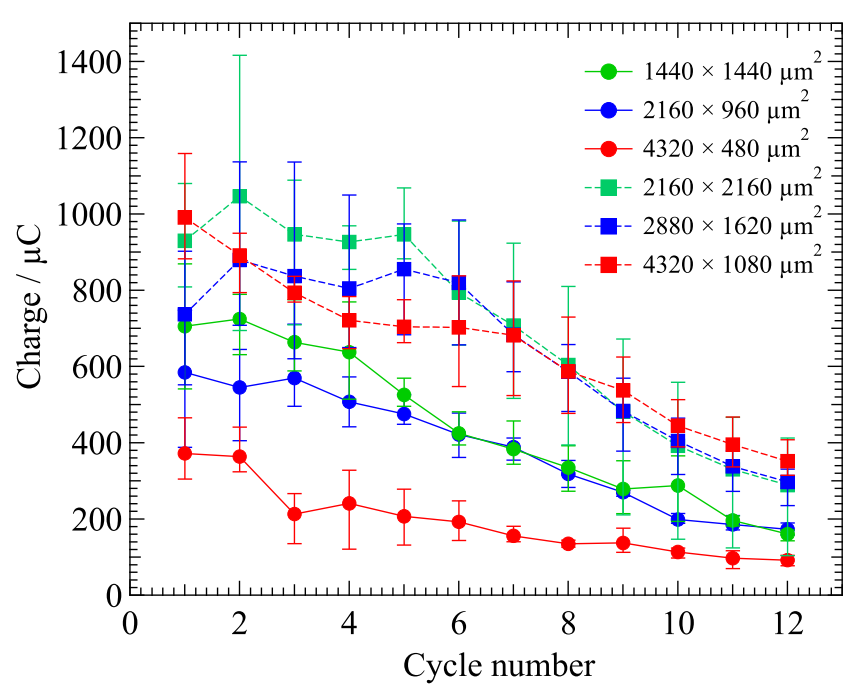

Fig. 6. Hydrogen permeation charges as a function of wet and dry cycle. (Online version in color.)

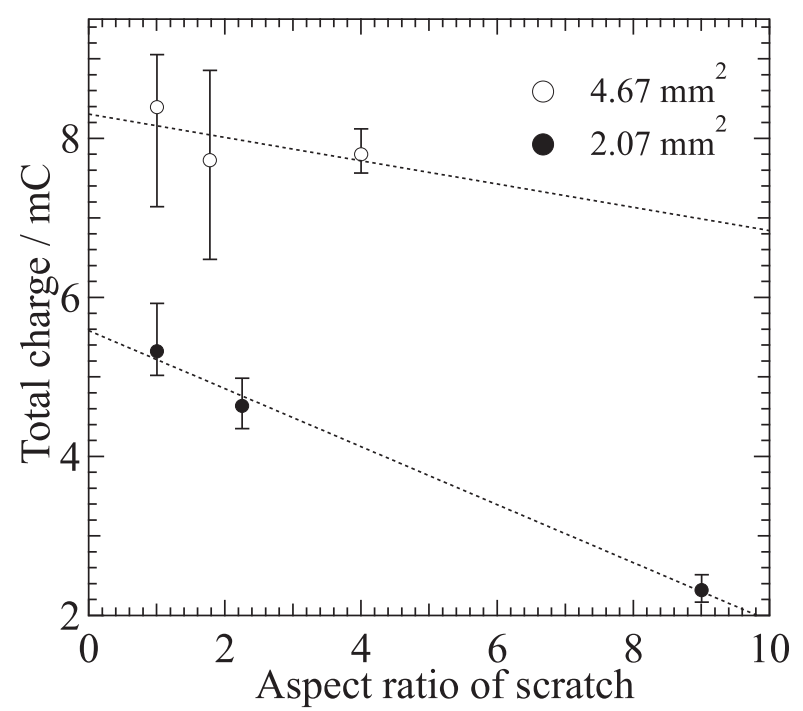

Fig. 7. Total hydrogen permeation charge as a function of aspect ratio of scratch. 
average of three specimens. The amount of hydrogen permeation charge decreases with the cycle numbers in all shapes.

Figure 7 shows the relationship between the total amount of hydrogen permeation charge for $72 \mathrm{~h}$ and the aspect ratio of the formed scratches. It can be seen that the larger the aspect ratio of the scratch, the smaller the total amount of charge, and the larger the area, the greater the total amount of charge.

\subsection{Surface Observation after the Tests}

In order to investigate the reason why the amount of hydrogen permeation charge decreases with the cycle numbers and the total amount of charge increase with scratch area but decrease with aspect ratio, the specimen surfaces after the tests were observed by optical microscope. Figure $\mathbf{8}$ is an optical microscope images of the specimens after the tests. There are white corrosion products around the scratches. It is confirmed that white corrosion products were composed of $\mathrm{Zn}, \mathrm{Cl}$ and $\mathrm{O}$ by EDS analysis.

The corrosion products are analyzed by Raman spectroscopy for further detailed observation. Figure 9 shows (a) optical microscope image of observed area and (b) the
Raman shift obtained from red circle in Fig. 9(a). The peaks at $210 \mathrm{~cm}^{-1}, 260 \mathrm{~cm}^{-1}, 390 \mathrm{~cm}^{-1}, 730 \mathrm{~cm}^{-1}, 910 \mathrm{~cm}^{-1}$, and $1030 \mathrm{~cm}^{-1}$ are assigned to simonkolleite $\left(\mathrm{Zn}_{5}(\mathrm{OH})_{8} \mathrm{Cl}_{2}\right) .{ }^{20)}$ From this result, it is found that the white corrosion products formed around the scratch are simonkolleite. ${ }^{21-23)}$

The reason why the hydrogen permeation charge decrease with the cycle numbers for all shapes is $\mathrm{Zn}$ corrosion products formation. If the area of $\mathrm{Zn}$ corrosion products increase with the cycle numbers, there are two possible mechanisms to explain the decrease in the hydrogen permeation charge with cycle number.

One mechanism is $\mathrm{Zn}$ corrosion products around the scratch inhibit the entry of hydrogen. ${ }^{18)}$ If the area of $\mathrm{Zn}$ corrosion products increase with the cycle numbers, the $\mathrm{Zn}$ corrosion product coverage of scratch increase. This causes decline of the number hydrogen entry sites and the amount of hydrogen permeation charge.

Second mechanism is the anodic dissolution rate of $\mathrm{Zn}$ decreases due to the fixation of $\mathrm{Cl}^{-}$by the formation of simonkolleite. Hayashi et al. reported that the anodic dissolution rate of $\mathrm{Zn}$ was third proportional to concentration of $\mathrm{Cl}^{-}$under neutral $(\mathrm{pH}=5-8)$ conditions. ${ }^{24)}$ As the low

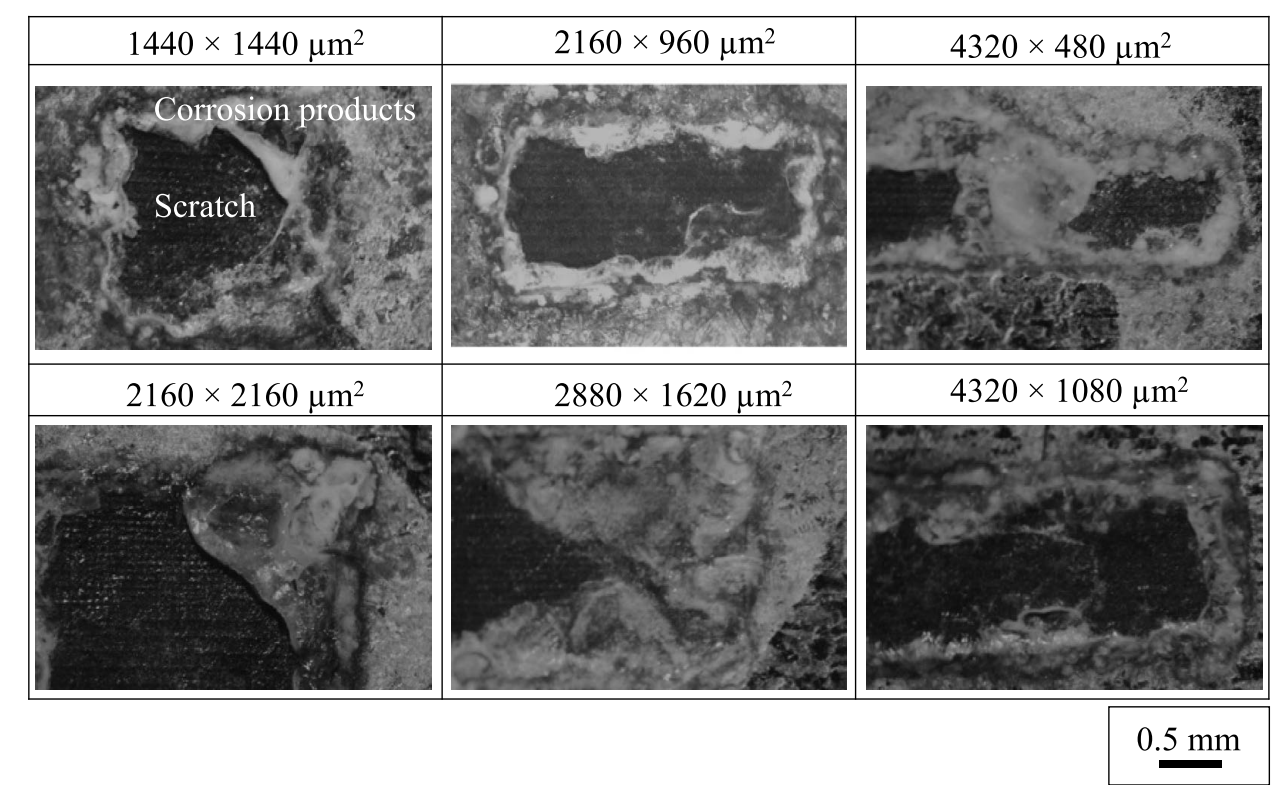

Fig. 8. Optical microscope images of specimens after wet and dry corrosion tests.
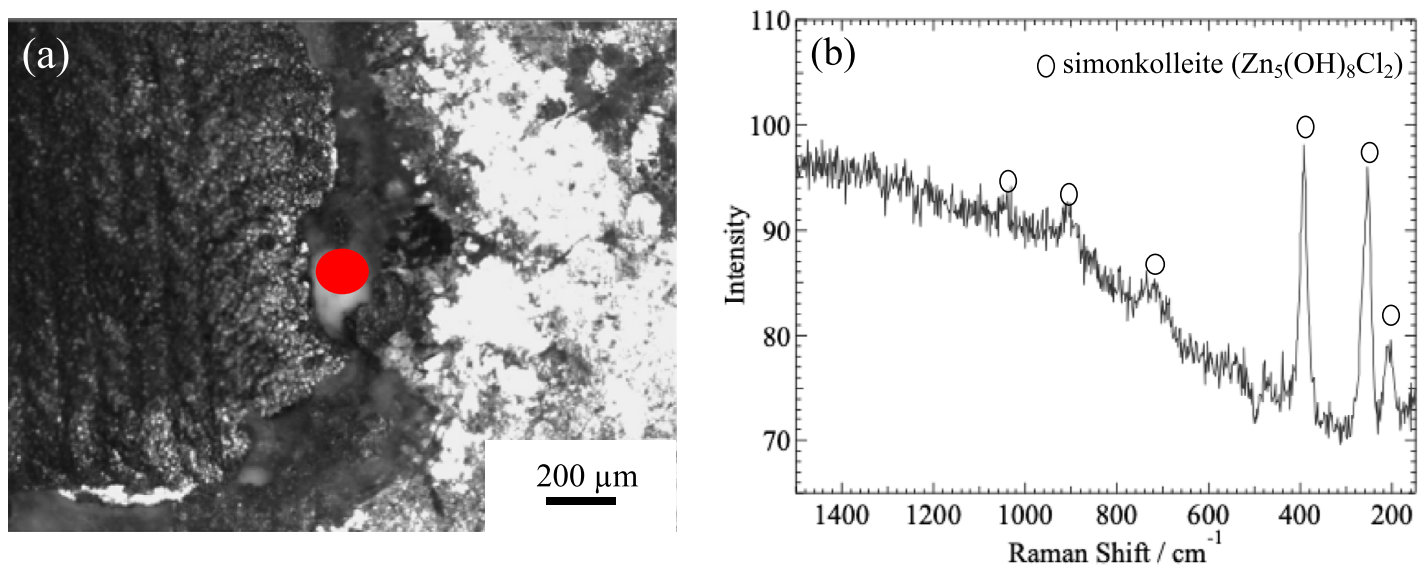

Fig. 9. (a) Optical microscope image and (b) Raman spectrum of white corrosion product formed around scratch (1 $\left.440 \times 1440 \mu \mathrm{m}^{2}\right)$ after wet and dry corrosion test. (Online version in color.) 
anodic $\mathrm{Zn}$ dissolution rate reduces the rate of hydrogen generation reaction, the amount of hydrogen permeation charge also decreases with the cycle numbers.

Islam et al. reported that $\mathrm{Zn}$ formed thin protective layer on steel surface after immersion test. ${ }^{25,26)}$ This thin $\mathrm{Zn}$ protective layer may inhibit corrosion reaction and hydrogen entry. Igarashi et al. reported that hydrogen permeation current after laser irradiation in the aqueous solution containing $\mathrm{Zn}^{2+}$ was smaller than that in the solution containing $\mathrm{Na}^{+}$or $\mathrm{Mg}^{+}{ }^{27}$ ) It is suggested that $\mathrm{Zn}$ make strong chemical binding with ion at steel surface and this thin $\mathrm{Zn}$ protective layer inhibit hydrogen entry. In order to investigate thin surface layer on steel at scratch, an AES analysis which can measure the thin surface layer was carried out. Figure 10(a) shows an SEM image of the specimen after the test, and an AES spectrum at the central part at red circle is shown in (b). The peaks are assigned to $\mathrm{O}(503 \mathrm{eV}), \mathrm{Fe}(599,652,704 \mathrm{eV})$ and $\mathrm{Zn}(990$ $\mathrm{eV}){ }^{28)}$ The $\mathrm{Zn}$ peak is observed in detail. Figure 11(a) shows the obtained AES spectrum at circle shown in Fig. 10(a), and the standard AES spectra of $\mathrm{ZnO}$ and $\mathrm{Zn}$. The $\mathrm{ZnO}$ and $\mathrm{Zn}$ standard spectrum are magnified by Table 1 magnification. The convolution of the $\mathrm{ZnO}$ and $\mathrm{Zn}$ standard spectra by leastsquares method and the obtained AES spectrum are shown in Fig. 11(b). Tsutsumi et al. reported that since the Auger transition involves outer shell electrons, the shape of the Auger peak reflects the chemical state of the specimen. ${ }^{29-32)}$ It is possible to analyze and quantify the chemical state by comparing the obtained peak shape with the standard spectrum. The calculated existence ratio from the magnification
Table 1. Magnification factor of standard materials spectra and existence ratio of $\mathrm{Zn}$ and $\mathrm{Zn}^{2+}$.

\begin{tabular}{ccc}
\hline Material & Magnification & Existence ratio \\
\hline $\mathrm{ZnO}$ & 0.2422 & $98.8 \%\left(\mathrm{Zn}^{2+}\right)$ \\
$\mathrm{Zn}$ & 0.0015 & $1.2 \%(\mathrm{Zn})$ \\
\hline
\end{tabular}

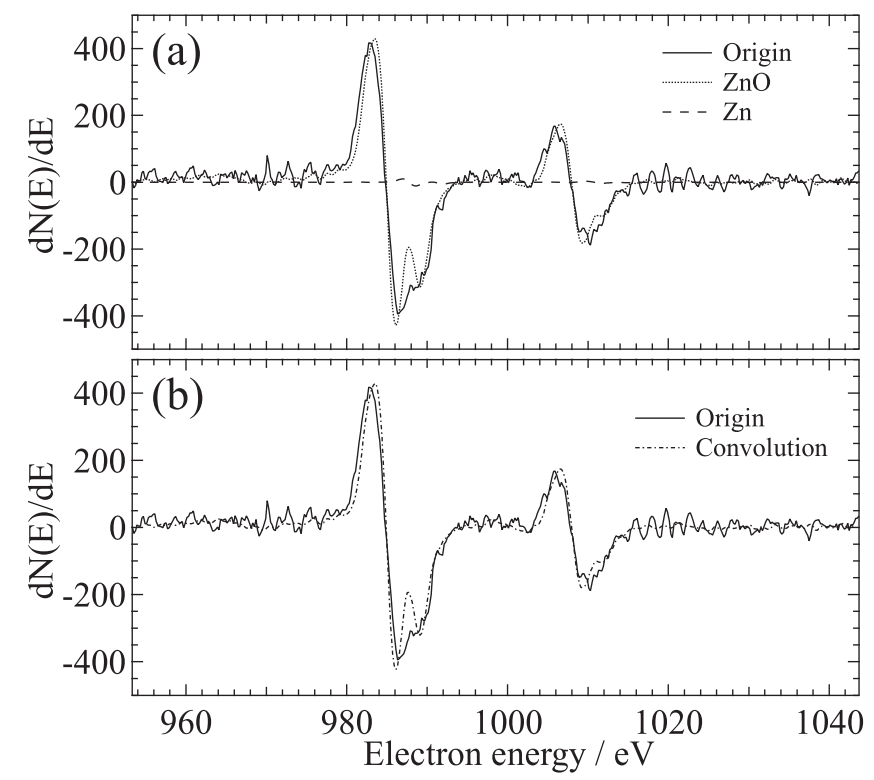

Fig. 11. AES spectrum of $1440 \times 1440 \mu \mathrm{m}^{2}$ scratch center. (a) Obtained spectra with $\mathrm{ZnO}$ and $\mathrm{Zn}$ standard spectrum after magnification, and (b) with convolution curve.
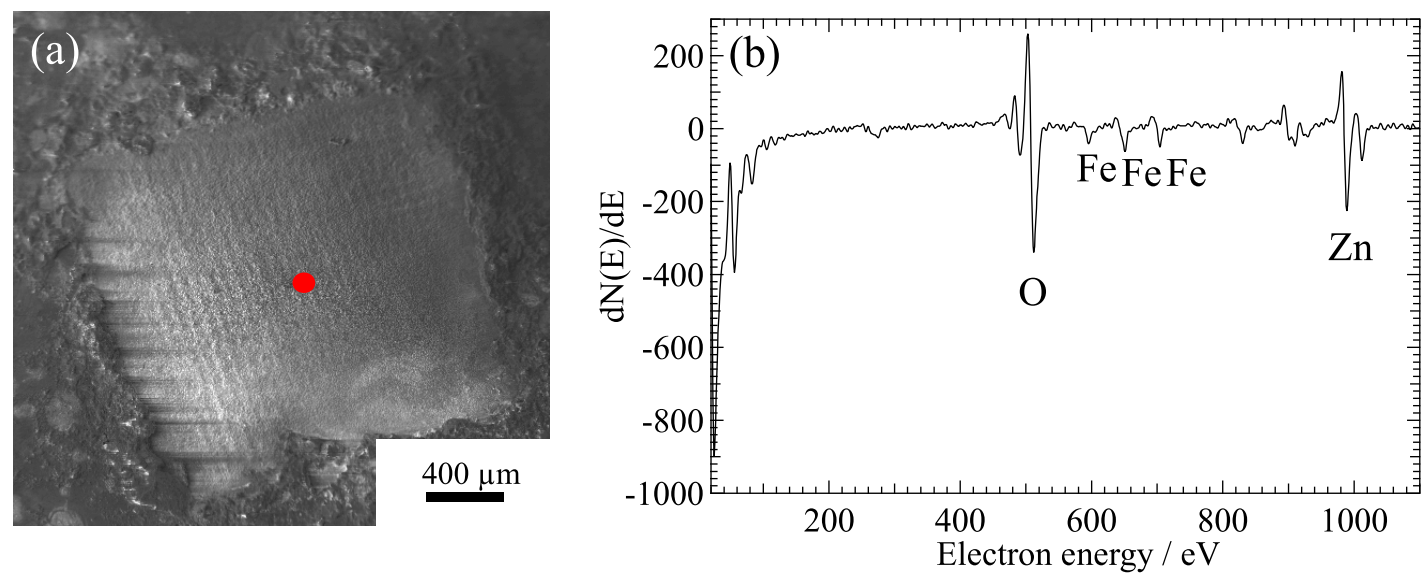

Fig. 10. (a) SEM image and (b) AES spectra obtained from $1440 \times 1440 \mu \mathrm{m}^{2}$ scratch center. (Online version in color.)

\begin{tabular}{|c|c|c|}
\hline Scratch area & Large $\left(4.67 \mathrm{~mm}^{2}\right)$ & Small $\left(2.07 \mathrm{~mm}^{2}\right)$ \\
\hline Aspect ratio & High & Low \\
\hline Hydrogen entry & Corrosion products & 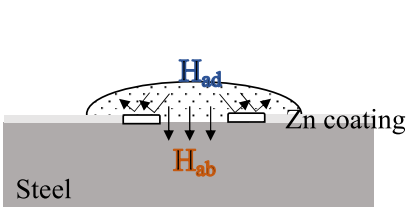 \\
\hline
\end{tabular}

Fig. 12. Schematic representation of difference of hydrogen entry with scratch area and aspect ratio. (Online version in color.) 
(a)

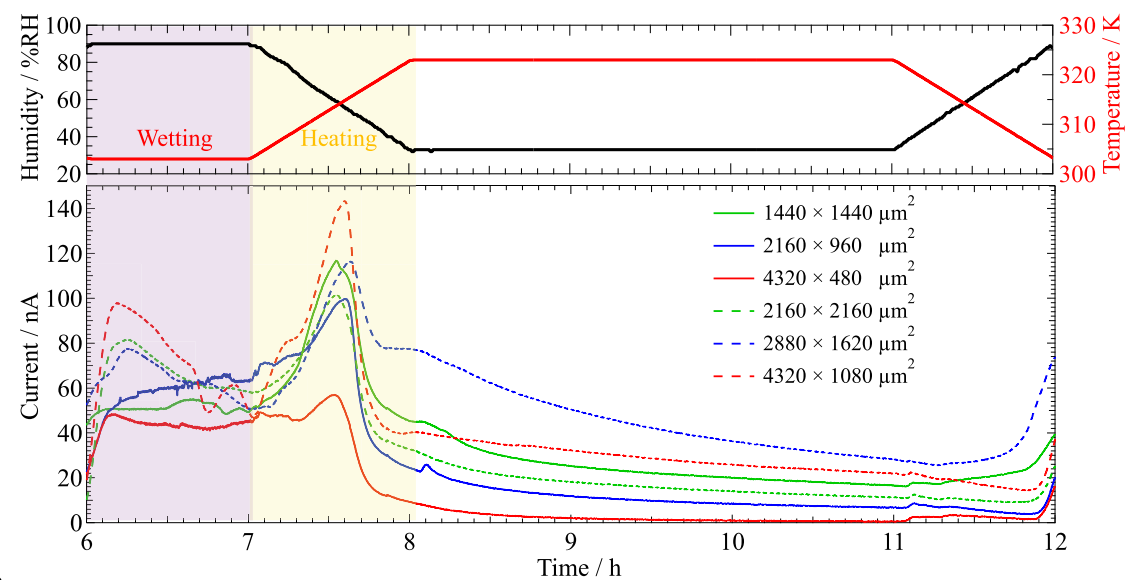

(b)
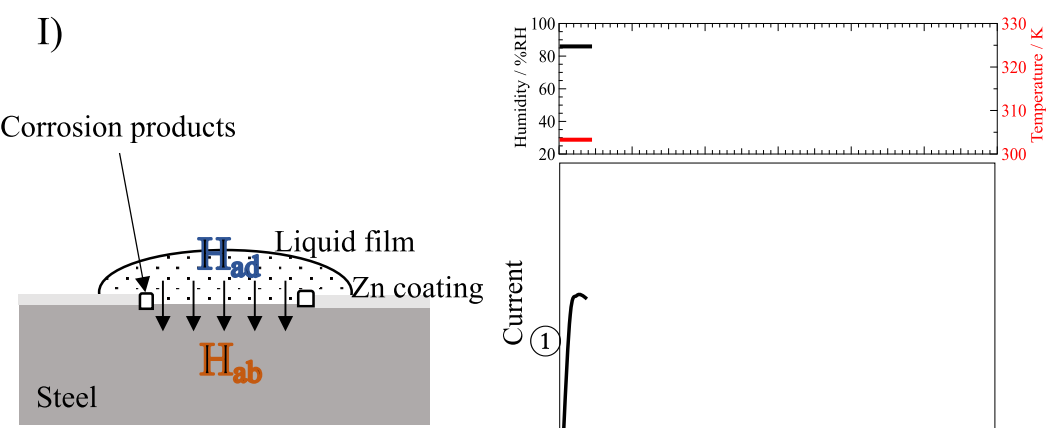

II)

Corrosion products
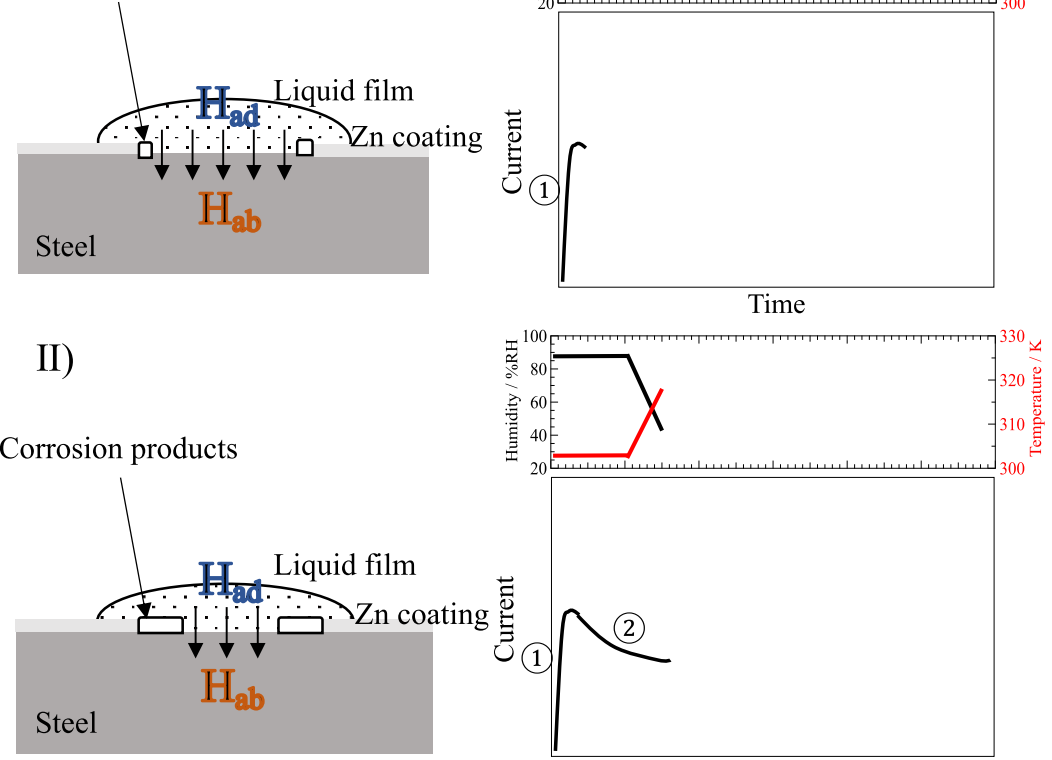

III)

Liquid film

( $\mathrm{NaCl}$ concentration: high)
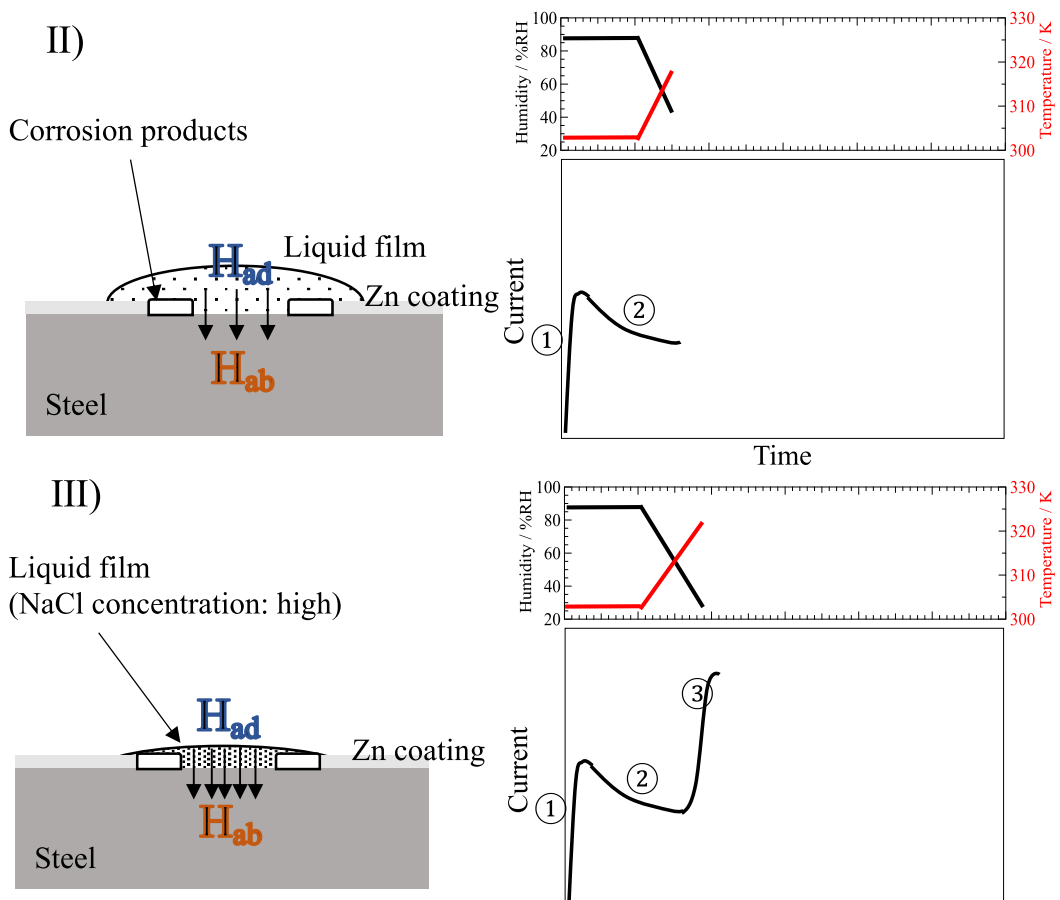

IV)
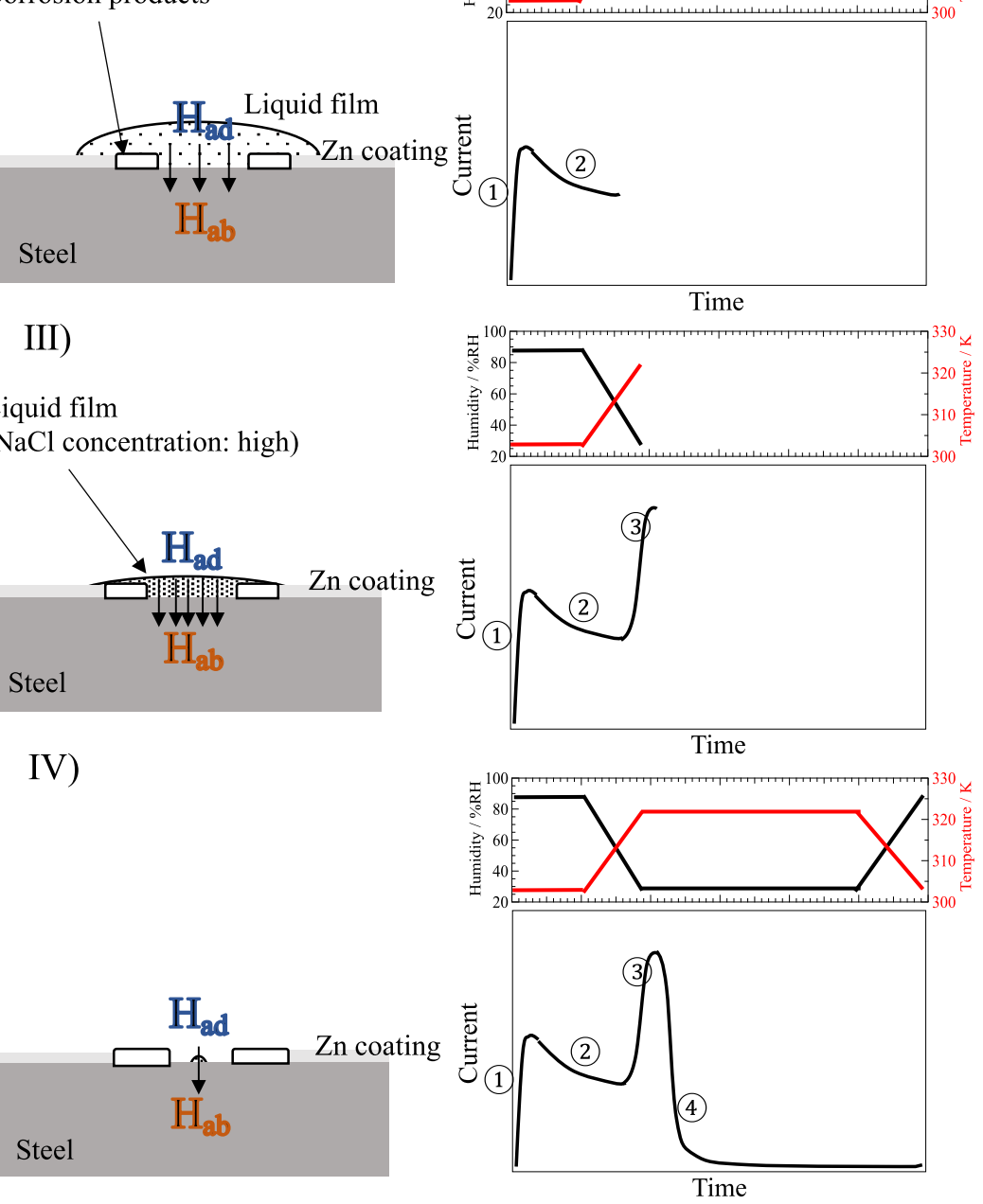

Fig. 13. (a) Changes in hydrogen permeation current during wet and dry corrosion tests of second cycle, and (b) Schematic representation of effect of humidity on hydrogen permeation current. (Online version in color.) 
is $98.8 \%$ for $\mathrm{ZnO}$ and $1.2 \%$ for $\mathrm{Zn}$. This result suggests that $\mathrm{ZnO}$ presented on the steel may inhibit hydrogen entry.

\subsection{Scratch Shape and Total Hydrogen Permeation Charge}

Figure 12 shows the schematic representation of hydrogen entry with different scratch area and aspect ratio. The reason why the total charge decrease with aspect ratio is formation of $\mathrm{Zn}$ corrosion products. Two mechanisms shown in 3.2 play an important role in the total charge. In the high aspect ratio scratch, $\mathrm{Zn}$ corrosion products easily covered the scratch. The total amount of charge of high aspect ratio scratch is less than that of low aspect ratio scratch because of tiny number of hydrogen entry site and the much amount of $\mathrm{Cl}^{-}$fixation.

The possible reason for total charge of $4.67 \mathrm{~mm}^{2}$ scratches is larger than that of $2.07 \mathrm{~mm}^{2}$ scratches is also formation of $\mathrm{Zn}$ corrosion products. $\mathrm{Zn}$ corromsion products form around and on the scratch, and the number of hydrogen entry site decreases. In large scratch, Zn corrosion products don't completely cover the scratch. The coverage of large scratch by $\mathrm{Zn}$ corrosion products might be less than that of small scratch. This causes remain of active hydrogen entry site.

\subsection{Hydrogen Permeation Current during One Cycle}

Figure 13(a) shows the 2nd cycle of the hydrogen permeation current during the wet and dry cycle test. It can be seen that each scratches in Fig. 13 have two peaks in the wetting and heating processes. Figure 13(b) shows the schematic representation of the surface state and the corresponding hydrogen permeation current behavior. I) A liquid film is formed on the surface during the wetting process, and the amount of hydrogen permeation current increases due to the sacrificial corrosion reaction of $\mathrm{Zn}$. II) The hydrogen permeation current is decreased by the generated $\mathrm{Zn}$ corrosion products. III) During the drying process, a second peak is observed. This is due to the evaporation of droplets and the $\mathrm{NaCl}$ concentration increases. This concentration change activates the sacrificial corrosion reaction again. IV) At the end of the drying process (from 8 to $12 \mathrm{~h}$ in Fig. 13(a)), the droplets completely evaporate and the corrosion reaction and hydrogen permeation do not occur.

\section{Conclusions}

In this study, the effects of scratch shape on the hydrogen permeation behavior of $\mathrm{Zn}$ coated steel during wet and dry cycle corrosion was investigated. Following conclusions may be drawn.

(1) The amount of hydrogen permeation charge decreases with the cycle numbers in all shapes.

(2) After the test, $\mathrm{Zn}$ corrosion products, simonkolleite $\left(\mathrm{Zn}_{5}(\mathrm{OH})_{8} \mathrm{Cl}_{2}\right)$, presented around and on the formed scratch. They prevented hydrogen entry and reduced corrosion reaction rate by fixing $\mathrm{Cl}^{-}$.

(3) The total hydrogen permeation charge decreased with aspect ratio because $\mathrm{Zn}$ corrosion products easily covered high aspect ratio scratch.

(4) The total hydrogen permeation charge of the $4.67 \mathrm{~mm}^{2}$ scratches was larger than that of the $2.07 \mathrm{~mm}^{2}$ scratches because $\mathrm{Zn}$ corrosion products hardly covered large scratch.

(5) Hydrogen permeation current during one cycle had two peaks in the wetting and heating processes. The sacrificial corrosion reaction of $\mathrm{Zn}$ and the $\mathrm{NaCl}$ concentration increased by evaporation caused two peaks.

\section{Acknowledgements}

SEM observation of this work was conducted at the Laboratory of XPS analysis, Joint-use facilities, Hokkaido University, supported by "Material Analysis and Structure Analysis Open Unit (MASAOU). XPS analysis was conducted at the Laboratory of XPS analysis, Hokkaido University, supported by 'Nanotechnology Platform' Program of the Ministry of Education, Culture, Sports, Science and Technology (MEXT), Japan.

\section{REFERENCES}

1) M. Kitagawa: Struct. Control Health Monit., 11 (2004), 75

2) A. R. Troiano: Corrosion, 15 (1959), 57.

3) M. Nagumo, M. Nakamura and K. Takai: Metall. Mater. Trans. A, 32 (2001), 339.

4) T. Schaffner, A. Hartmaier, V. Kokotin and M. Pohl: J. Alloys Compd., 746 (2018), 557.

5) T. Michler, Y. Lee, R. P. Gangloff and J. Naumann: Int. J. Hydrog. Energy, 34 (2009), 3201.

6) K. Ebihara, T. Iwamoto, Y. Matsubara, H. Yamada, T. Okamura, W. Urushihara and T. Omura: ISIJ Int., 54 (2014), 153.

7) H. Hatano, M. Fujinami, K. Arai, H. Fujii and M. Nagumo: Acta Mater., 67 (2014), 342.

8) M. Koyama, H. Springer, S. V. Merzlikin, K. Tsuzaki, E. Akiyama and D. Rabbe: Int. J. Hydrog. Energy, 39 (2014), 4634.

9) A. Nagao, C. D. Smith, M. Dadfarnia, P. Sofronis and I. M. Robertson: Procedia Mater. Sci., 3 (2014), 1700.

10) T. Matsuno, Y. Sekito, E. Sakurada, T. Suzuki, K. Kawasaki and M. Suehiro: ISIJ Int., 54 (2014), 2369.

11) A. Nagao, M. L. Martin, M. Dadfarnia, P. Sofronis and I. M. Robertson: Acta Mater., 74 (2014), 244.

12) D. Hirakami, T. Manabe, K. Ushioda, K. Noguchi, K. Takai, Y. Hata, S. Hata and H. Nakashima: Tetsu-to-Hagané, 101 (2015), 59 (in Japanese).

13) T. Michler, J. Naumann, M. Hock, K. Berreth, M. P. Balogh and E. Sattler: Mater. Sci. Eng. A, 628 (2015), 252.

14) I. Park, S. Lee, H. Jeon and Y. Lee: Corros. Sci., 93 (2015), 63.

15) T. Kushida: ISIJ Int., 43 (2003), 470.

16) S. Fujita and D. Mizuno: Corros. Sci., 49 (2007), 211.

17) E. Tada and Y. Miura: ISIJ Int., 56 (2016), 444.

18) K. Igarashi and M. Sakairi: ISIJ Int., 56 (2016), 465.

19) S. Ootsuka, S. Fujita, E. Tada, A. Nishikata and T. Tsuru: Corros. Sci., 98 (2015), 430.

20) M. C. Bernard, A. Hugot-Le Goff, D. Massinon and N. Phillips: Corros. Sci., 35 (1993), 1339.

21) J. Kasperek and M. Lenglet: Metall. Res. Technol., 94 (1997), 713.

22) T. Ohtsuka and Y. Abe: Proc. Galvatech '07, ISIJ, Tokyo, (2007), 648.

23) T. Ohtsuka and M. Matsuda: Corrosion, 59 (2003), 407.

24) K. Hayashi and Y. Miyoshi: Tetsu-to-Hagané, 78 (1992), 601 (in Japanese).

25) M. S. Islam, K. Otani and M. Sakairi: ISIJ Int., 58 (2018), 1616.

26) M. S. Islam, K. Otani and M. Sakairi: Corros. Sci., 131 (2018), 17.

27) T. Igarashi, K. Otani, C. Kato, M. Sakairi, Y. Togashi, K. Baba and S. Takagi: ISIJ Int., 61 (2021), 1083.

28) T. Sekine, Y. Nagasawa, M. Kudoh, Y. Sakai, A. S. Parkes, J. D. Geller, A. Mogami and K. Hirata: Handbook of Auger Electron Spectroscopy, JEOL Ltd., Tokyo, (1982), 28.

29) K. Tsutsumi, A. Tanaka, M. Shima and T. Tazawa: J. Surf. Sci. Soc. Jpn., 33 (2012), 431 (in Japanese).

30) K. Tsutsumi: J. Surf. Finish. Soc. Jpn., 66 (2015), 621 (in Japanese).

31) K. Tsutsumi, Y. Nagasawa, H. Watanabe and S. Endo: Proc. 26th Japan Society of Vacuum and Surface Science conf., The Surface Science Society of Japan, Tokyo, (2006), 4D23 (in Japanese). https:// doi.org/10.14886/sssj.26.0.290.0

32) K. Tsutsumi, A. Tanaka and M. Shima: Proc. Japan Society of Vacuum and Surface Science conf., The Japan Society of Vacuum and Surface Science, Tokyo, (2018), 3Bp11 (in Japanese). https://doi. org/10.14886/sssj2008.2018.0 336 